\title{
The Relationship between Principals' Technology Leadership and Teachers' Technology Use in Malaysian Secondary Schools
}

\author{
Arumugam Raman ${ }^{1}$, Yahya Don ${ }^{1} \&$ Abd. Latif Kasim ${ }^{1}$ \\ ${ }^{1}$ School of Education and Modern Languages, Universiti Utara Malaysia, Sintok, Malaysia \\ Correspondence: Arumugam Raman, School of Education and Modern Languages, Universiti Utara Malaysia, \\ Sintok, Kedah, Malaysia. Tel: 60-4-4928-4852. E-mail: arumugam@uum.edu.my
}

Received: April 30, 2014 Accepted: July 11, 2014 Online Published: August 15, 2014

doi:10.5539/ass.v10n18p30

URL: http://dx.doi.org/10.5539/ass.v10n18p30

\begin{abstract}
The aim of the study is to examine of technology usage in Malaysian secondary schools and the influence of principals on technology use. This study focuses on principals' technology leadership behavior according to the National Educational Technology Standards for Administrators (NETS-A). The sample for this study consisted of 115 principals from public schools in Kedah, Malaysia. Two survey instruments were used in this study. First, the Principals Technology Leadership Assessment PTLA survey is to measure the independent variable, Principals' Leadership Behaviour. Secondly, a TTU (Teachers Technology Use) to measure teachers' technology use in schools. The relationship between PTLA and TTU was measured using a simple linear regression analysis. The study revealed that the PTLA was not found to be a good predictor of school technology use, $F(1,83)=$ $12.48, p<.0005$ and principals' technology behavior accounted for $12.1 \%$ of explained variability in teachers' technology use in the classroom. The regression equation is as follows: Teachers' Technology Use (TTU) $=$ $-0.825+0.037$ (PTLA score). Thus the equation shows that one unit of change in PTLA score could increase the teachers' technology use by .04. Finally, the implications for principals as well as teachers are discussed.
\end{abstract}

Keywords: principals, technology, technology leadership, ISTE, school sechnology use, leadership behaviour

\section{Introduction}

The Prime Minister of Malaysia has announced a total of RM54.6 billion (MOF, 2013) for the education sector to improve technology usage in Malaysian schools. Many programs have been highlighted via computer lab projects by the Ministry of Education to provide opportunities for all primary and secondary school students to gain 21st century skills, particularly in Information and Communication Technology (ICT). These skills will enable Malaysian students to compete in the world of information. Although the government has been able to formulate a strong framework for enhancement of technology education in schools, their plans are very reliant on the implementation group, which consists of principals, teachers, students, and parents. This study focuses on the role of principals to turn the government's mission into reality. The principal plays a vital role to ensure technology integration in schools according to the government vision. He or she is also responsible for implementing educational policies initiated by the Ministry of Education (MOE); which without their cooperation, national education policy would be unlikely to be successful. Thus, the researcher wishes to explore and measure the relationship between the principal technology leadership behaviour and technology usage in Malaysian secondary schools. Drastic changes constantly occur in the world of technology. In order to pursue education according to the latest technology, principals must have the capacity to address the complex changes and cultivate an organizational culture of continuous learning (Anderson \& Dexter, 2005). Previous studies have determined the variables which directly impact a principal's technology behaviour and technology use in schools; however, moderating variables such as computer efficacy, attitude, and gender were omitted.

\section{Literature Review}

Many evidences show that principals leadership behaviour influence on technology usage in schools (Anderson \& Dexter, 2005). Anderson \& Dextor (2005) conclusions backed the claim that principals influence technology results via their leadership behaviour as defined by International Society for Technology in Education (ISTE, formerly known as the National Educational Technology Standards-Administrators-NETS-A). ISTE suggests five critical areas to identify principals influence on technology outcomes: i) visionary leadership, ii) digital age learning culture, iii) excellence in professional practice, iv) systematic improvement, and v) digital citizenship. 


\section{1) Visionary leadership}

Educational Administrators inspire and lead development and implementation of a shared

vision for comprehensive integration of technology to promote excellence and support transformation throughout the organization (ISTE, 2014).

\section{2) Digital age learning culture}

Educational Administrators create, promote, and sustain a dynamic, digital-age learning culture that provides a rigorous, relevant, and engaging education for all students (ISTE, 2014).

\section{3) Excellence in professional practice}

Educational Administrators promote an environment of professional learning and innovation that empowers educators to enhance student learning through the infusion of contemporary technologies and digital resources (ISTE, 2014).

\section{4) Sytematic improvement}

Educational Administrators provide digital age leadership and management to continuously improve the organization through the effective use of information and technology resources ISTE, 2014).

\section{5) Digital citizenship}

Educational Administrators model and facilitate understanding of social, ethical and legal issues and responsibilities related to an evolving digital culture (ISTE, 2014).

The first critical area visionary leadership wield substantial effect on technology outcomes (Ertmer, Bai, Dong, Khalil, Park, \& Wang, 2002; Anderson \& Dexter, 2005). According to Porter, (2003) and Kowch, (2005), the principal's role in designing technology planning is crucial for developing a vibrant mission along achievable objectives. Gosmire and Grady (2007) also suggested that principals play a role in encouraging teachers to use technology in their classroom. A study conducted by Dawson \& Rakes (2003) confirmed that principals determine the extent of technology integration in the classroom. Generally, previous studies have proposed that the principals should possess basic knowledge about the role of computers in the teaching and learning process and enable them to develop technology-infused strategic plan to align with a shared vision (Owens, 2003).

After the release of NETS-A, many studies were conducted to examine principals' technology proficiency, integration, and leadership in schools. Kadela (2002) investigated the technology leadership standards and how the technology integrated into the educational setting. His study revealed principals' behaviours in technology integration and technology leadership within the school community. Another study, conducted to examine computer technology use and technology leadership in Texas (Fisher \& Waller, 2013), described high level computer technology use, particularly computer tools linking communication. Further, the study reported on high-level leadership performance based on NETS-A standards. A multiple analyses of variance (MANOVA) showed no significant difference in mean scores between computer use or leadership performance in terms of NETS-A standards and the independent variables such as region, spending per head, campus status, and title. Conversely, a first regression analysis indicates a positive relationship between principals' technology use and training and risk benefits. A second regression analysis revealed a significant relationship between principals' technology leadership to NETS-A standards and training, risk benefit and perceived pressure. However, multiple regression shows no correlation between technology use (dependent variable) and technology leadership (Weber, 2006). A study conducted by Miller (2007) found significant professional development needs of NETS-A. Page-Jones (2008) studied the relationship between principal's technology efficiency and technology leadership and found a strong relationship between technology leadership behaviors and the use of technology in schools. Oubre (2007) conducted a study on technology leadership proficiency based on NETS-A and found statistically insignificant relationships between NETS-A proficiency and other variables such age, training, attitudes, professional development, and employment history. Further, the study also revealed that administrators believed that formal training does not prepare them for technology leadership.

\subsection{Problem Statement}

The above literature suggests the technology leadership varies according to schools, age, risk benefit and area. The study also shows that principals are the driving factor in successful technology use by teachers. A few studies have described principals' best practices to prepare themselves to be effective technology leaders. Therefore, there is a need to examine the relationship between technology leadership and teachers' technology use in schools. Furthermore, no study has looked into Malaysian secondary school principals' technology leadership and the relationship with teachers' technology use. 
The main hypothesis for this study is:

$\mathrm{H}_{0}: \mathrm{b}_{1}=0$, the coefficient of the slope equals 0 (zero)

\section{Method}

\subsection{Sampling}

The population of this study consisted of 183 secondary school principals and 520 teachers in the Kedah state of Malaysia. At the time of research, there were 183 schools composed of 151 National Secondary Schools, 4 National Vocational Schools, one National Technical School, 4 National Religious Schools, 5 Boarding Schools, 15 Government Funded Religious Schools and two special 'Model Schools' (Secondary + Primary) (State Education Department, 2014). The principals from the religious secondary schools and special model schools were excluded from the sample because of different organizational structures. The researcher used random sampling and 118 principals and 234 teachers were selected (Krejcie \& Morgan, 1970).

\subsection{Instrument}

The Principal Technology Leadership Survey Assessment (PTL) was used to measure the principal's technology leadership (dependent variable) and Teachers Technology Use Survey (TTU) to measure the use of technology in classroom. The PTL survey was modified from previous research (Judith, 2011; Shannon, 2011) and ISTE standards for Administrators (ISTE, 2009); whereas TTU was adopted and modified from Jamieson and Finger (2003) and Jamieson, Finger and Albion (2010). Both surveys were administered via 'Google Form'. ISTE was developed to help principals implanting technology in their schools. It consists of five sections: i) visionary leadership (1-6 items), ii) digital age learning culture (7-11 items), iii) excellence in professional practice (12-17 items), iv) systematic improvement (18-26 items) and v) digital citizenship (27-35 items). The questionnaire consisted of a total of 35 questions with five-point scale from "not at all" to "fully" (Likert scale) and respondents were asked to circle their level of agreement with each item. The TTU consists of 19 items with four-point Likert style scale from "not at all" to "very great extent".

\subsection{Survey Reliability and Validity}

Experts' opinions were used to establish the content validity of the items. Only three items were dropped after they were found to measure the same construct. The draft instrument was reviewed and revised accordingly before being sent to the respondents. A pilot study was conducted to measure the reliability of the instrument. A total of 20 principals and 25 teachers responded from different parts of the research area. The reliability of the instrument (PTL) is very high with Cronbach alpha $(\alpha)=0.92$, while alpha $(\alpha)=0.89$ for TTU.

\section{Results}

Only 85 principals and 192 teachers responded to the questionnaires. The response rate is $89 \%$ for principals and $82 \%$ for teachers, respectively.

All analyses were conducted with Statistical Package for the Social Sciences (SPSS v20). Table 1 shows the total number of principals based on gender.

Table 1. Principals based on gender

\begin{tabular}{ll}
\hline Gender & Percentage $(\%)$ \\
\hline Male & 55 \\
Female & 45 \\
\hline
\end{tabular}

Table 2 shows the mean and standard deviations for each construct scale. The scale (20-30) indicated strong leadership, while (16-19) indicated moderate and (0-15) indicated weak leadership (Page-Jones, 2008).

Table 2. Mean and standard deviations for each construct

\begin{tabular}{lll}
\hline Construct & Mean & Standard Deviation \\
\hline Visionary Leadership & 21.44 & 2.85 \\
Digital Age Learning Culture & 24.18 & 2.67 \\
Excellence In Professional Practice & 21.40 & 2.78 \\
Systematic Improvement & 19.24 & 3.37 \\
Digital Citizenship & 25.10 & 5.24 \\
\hline
\end{tabular}


The 'Digital Citizenship' construct has the highest mean (25.10) with the highest standard deviation (5.24). The mean of four constructs fell in the range of 20 to 30, indicating a strong level of technology leadership.

Table 3 shows $32 \%$ male and $68 \%$ female teachers responded the questionnaire. The number of female teachers was double that of male teachers.

Table 3. Teachers based on gender

\begin{tabular}{ll}
\hline Gender & Percentage (\%) \\
\hline Male & 32 \\
Female & 68 \\
\hline
\end{tabular}

Table 4 shows the mean and standard deviations (SD) for each item. The score range (36-56) indicates teachers strongly agree with technology use, (16-35) indicates moderate use of technology, and (0-15) shows little agreement with technology use in teaching.

Table 4. Teacher's technology use

\begin{tabular}{llll}
\hline Item & I am using technology to: & Mean(SD) & Usage Score \\
\hline 1 & gain knowledge, skills, capabilities, and attitude to work continuously & $2.38(.85)$ & 35.2 \\
2 & $\begin{array}{l}\text { develop functional competency in the curriculum field that has been } \\
\text { determined. }\end{array}$ & $2.45(.95)$ & 33.2 \\
3 & synthesize their knowledge. & $2.72(.98)$ & 41.0 \\
4 & participate in constructing their own knowledge in cooperating with their & $2.65(1.00)$ & 28.0 \\
& friends and others & & \\
5 & participate in constructing knowledge that integrates the curriculum field. & $2.56(.85)$ & 32.2 \\
6 & construct in depth understanding interesting topics related to the curriculum & $2.72(.85)$ & 34.8 \\
7 & field that is studied. & $2.45(.95)$ & 39.5 \\
8 & develop scientific understanding of the world. & $2.75(.92)$ & 28.4 \\
9 & give motivation for curricular tasks. & $2.60(.85)$ & 23.1 \\
10 & plan and / or manage curricular projects. & $2.50(.80)$ & 39.8 \\
11 & integrate different media to create appropriate products. & $2.65(.95)$ & 45.2 \\
12 & support learning process elements. & $2.85(.78)$ & 20.5 \\
13 & cemonstrate what they have learned. & $2.72(.96)$ & 29.5 \\
14 & be aware of the global implication of ICT based technology on societies. & $2.50(.85)$ & 38.5 \\
15 & gain intercultural understanding. & $2.61(.75)$ & 36.5 \\
16 & assess themselves and society values critically. & $2.45(.90)$ & 31.7 \\
17 & communicate with others in and at global level. & $2.75(1.00)$ & 30.4 \\
18 & get involved in independent learning through access to education at their & $2.75(.99)$ & 32.5 \\
& own time, place and pace. & $2.50(1.05)$ & 31.2 \\
\hline
\end{tabular}

The highest score is 'support learning process elements' (45.2), whereas the lowest is 'plan and/ manage curricular projects' (23.1). Most of the items are moderate, and no items show little agreement.

The researcher used a simple linear regression analysis to discover a relationship between the technology leadership behaviour and the teachers' technology use in the classroom. The analysis shows simple linear regressions assumptions such as linearity, normality (skewness (-.743) and kurtosis (1.32)), independence, and homogeneity of variance were tested.

Table 5 shows the analysis of correlation confirmed the accuracy of the model. In this case, $R=0.389$, which indicates a moderate correlation and $\mathrm{R}^{2}=0.121$, which means that the independent variable PTLA explains 12.1 of the variability of the dependent variable. Adjusted $\mathrm{R}^{2}$ is also an estimate of the effect size, which at 0.143 
$(14.3 \%)$ is indicative of a medium effect size, according to Cohen's (1988) classification.

Table 5. Model summary

\begin{tabular}{llllll}
\hline Model & R & R Square & Adjusted R square & Std. Error of the Estimate & Durbin-Watson \\
\hline 1 & $0.328^{\mathrm{a}}$ & .121 & .143 & .53759 & .927 \\
\hline
\end{tabular}

a. Predictors: (constant), PTLA

b. Dependent variable: Teachers Technology use

The ANOVA table (Table 6) determines whether the regression model results in a statistically significantly better prediction of the dependent variable (teacher's technology use).

Table 6. ANOVA

\begin{tabular}{llllll}
\hline Table 6 ANOVAa: Model & Sum of Squares & df & Mean Square & F & Sig. \\
\hline Regression & 3.470 & 1 & 3.470 & 12.48 & $.000^{b}$ \\
Residual & 23.385 & 84 & .278 & & \\
Total & 26.856 & 85 & & & \\
\hline
\end{tabular}

a. Dependent Variable: Teachers Technology Use

b. Predictors: (constant), PTLA

Based on table 6, technology leadership behaviour as measured in PTLA score of principals is a good predictor of teachers technology use in the classroom. A linear regression established that principal technology behaviour could statistically significantly predict teachers' technology use, $F(1,83)=12.48, p<.0005$ and principals technology behaviour accounted for $12.1 \%$ of explained variability in teachers' technology usage in classroom.

4.1 Predicting the Teachers' Technology Use

Table 7 shows parameter estimation. The researchers derive the regression equation based on this table.

Table 7. Parameter estimates (Coefficients) ${ }^{\mathrm{a}}$

\begin{tabular}{llllllll}
\hline \multirow{2}{*}{ Model } & \multicolumn{2}{l}{$\begin{array}{l}\text { Unstandardized } \\
\text { Coefficients }\end{array}$} & $\begin{array}{l}\text { Standardized } \\
\text { Coefficients }\end{array}$ & $\mathrm{t}$ & $\mathrm{Sig}$ & \multicolumn{2}{l}{$95.0 \%$ Confidence Interval for B } \\
& $\mathrm{B}$ & Std. Error & Beta & & & Lower Bound & Upper Bound \\
\hline 1 (Constant) & -0.825 & 1.677 & .3542 & -.526 & .574 & -4.270 & 2.124 \\
PTLA (Score) & 0.037 & 0.10 & & 3.792 & .000 & .017 & 0.52 \\
\hline
\end{tabular}

a. Dependent variable: TTU

The regression equation is as follows:

Teachers' Technology Use (TTU) $=\mathbf{- 0 . 8 2 5}+\mathbf{0 . 0 3 7}$ (PTLA score).

The equation predicting that one unit change in principal's technology leadership behaviour score could increase the level of teachers' technology use in classroom by 0.04 .

\section{Discussion}

This research fits with previous studies which revealed that principals' impact on their teachers technology use in schools was significant (Halligner \& Heck, 1998). Further, this study also proves that the power of principals' technology practice in educational organizations can be measured (Anderson \& Dexter, 2005). The ANOVA rejected the null hypothesis that there is no relationship between the principal's technology behaviour and the teachers' technology use in schools. 


\subsection{Implications for Teachers}

The survey clearly showed that teachers adopted technology in teaching and learning process. From the principals' view point, teachers are required to enhance their technology skills for the greater use in future. Malaysia's Education Blueprint targeted to provide full Internet access for 10,000 schools nationwide by the end of 2013 (MOE, 2013). Teachers should be aware that paper-based items, such as student report card, test results and communication between parents are becoming digitized. They are also required to take precautions in case of hard disk failure, human error, or theft. They must have their own external backup devices to backup all data needed for future use. The fundamental implication for teachers is to encourage the wider use of technology beyond basic applications such as word processing, spreadsheets, presentations, and databases. Using software tools such as web development, learning management systems, and learning objects help them to integrate technology effectively and efficiently. Teachers should encourage students to share their experience and provide feedback via Internet communication tools such as blogs, learning portals and e-mails.

\subsection{Implications for Principals}

The findings of this research are consistent with other research asserting that principals have become role model to teachers in daily practice. The principals should be involved in designing and in preparing schools' technology strategic plan. This strategy should align with national, state and district technology agenda. Human capital is one of the most valuable assets in an educational setting. Principals' technology knowledge and skills considered valuable investment for the school growth. They may use technology such as blogs, online discussion boards, and intelligent systems to run the school efficiently.

\subsection{Conclusion}

There are some limitations in this study. The study was conducted in only one state of Malaysia. There are 12 other states which were not included in this study. Future researchers should consider a wide range of population and teachers. It is suggested future researchers to design quantitative and qualitative methodologies that will produce more solid relationship between principals' technology behaviour and teachers' technology use in schools.

\section{References}

Albion, P. R., Jamieson-Proctor, R., \& Finger, G. (2010). Auditing the TPACK confidence of Australian pre-service teachers: The TPACK confidence survey (TCS). In Proceedings of the 21st International Conference of the Society for Information Technology \& Teacher Education (SITE 2010) (Vol. 1, pp. 3772-3779). Association for the Advancement of Computing in Education (AACE).

Anderson, R. E., \& Dexter, S. (2005). School technology leadership: An empirical investigation of prevalence and effect. Educational Administration Quarterly, 41(1), 49-82. http://dx.doi.org/10.1177/0013161X0 4269517

Dawson, C., \& Rakes, G. (2003). The influence of principals' technology training on the integration of technology into schools. Journal of Research on Technology in Education, 36(1), 29-49. http://dx.doi.org/10. 1080/15391523.2003.10782401

Ertmer, P. A., Bai, H., Dong, C., Khalil, M., Park, S. H., \& Wang, L. (2002). Online professional development: Building administrators' capacity for technology leadership. Journal of Computing in Teacher Education. Retrieved March, 2014, from http://www.edci.purdue.edu/ertmer/docs/NECCO2_TIPDOC_paper.PDF

Fisher, D. M., \& Waller, L. R. (2013). The 21st Century Principal: A Study of Technology Leadership and Technology Integration in Texas K-12 Schools. The Global ELearning Journal Volume, 2(4).

Gosmire, D., \& Grady, M. L. (2007). A Bumpy Road: Principal as Technology Leader. Principal Leadership, $7(6), 16-21$.

Hallinger, P., \& Heck, R. H. (1998). Exploring the Principal's Contribution to School Effectiveness: 1980-1995. School effectiveness and school improvement, 9(2), 157-191. http://dx.doi.org/10.1080/0924345980090203

International Society for Technology in Education (ISTE). (2009). NETS for administrators. Retrieved from http://www.iste.org/Content/NavigationMenu/NETS/ForAdministrators/2009Standards/NETS_for_Adminis trators_2009.htm

International Society for Technology in Education (ISTE). (2014, July 1). ISTE standards administrators. Retrieved from http://www.iste.org/standards

Jamieson-Proctor, R., \& Finger, G. (2006). Relationship between pre-service and practicing teachers' confidence 
and beliefs about using ICT. Australian Educational Computing, 21(2), 25-33.

Jamieson-Proctor, R., Finger, G., \& Albion, P. (2010). Auditing the TPACK capabilities of final year teacher education students: Are they ready for the 21st century? In Proceedings of the 2010 Australian Computers in Education Conference (ACEC 2010) (pp. 1-12). Australian Council for Computers in Education.

Judith, E. G. (2010). The study of technology leadership among elementary public school Miami Dade County. (Doctoral dissertation). St. Thomas University, Miami, Florida.

Kadela, T. (2002). Technology leadership of elementary principals: Standards, competencies and integration. Dissertation Abstracts International ATT 3066135.

Kowch, E. (2005). Do we plan the journey or read the compass? An argument for preparing educational technologists to lead organizational change. British Journal of Educational Technology, 26(6), 1067-1070. http://dx.doi.org/10.1111/j.1467-8535.2005.00577.x

Krejcie, R. V., \& Morgan, D. W. (1970). Determining size for research activities. Educational and Psychological Measurement, 30, 607-610.

Miller, M. L. (2007). A mixed-method study to identify aspects of technology leadership in elementary schools. (Unpublished doctoral dissertation). Regent University, Virginia Beach, VA.

Ministry of Education. (2013). Malaysian Education Blueprint 2013-2025. Kementerian Pelajaran Malaysia: Percetakan Nasional Malaysia Berhad.

Ministry of Finance. (2012). Bajet 2013. Kementerian Kewangan Malaysia. Kuala Lumpur: Percetakan Nasional Malaysia Berhad.

Oubre, A. J. (2007). Technology leadership proficiency among school administrators in the twenty-first century schools. (Unpublished doctoral dissertation). The University of Southern Mississippi, Hattiesburg.

Owens, T. S. (2003). Study of innovative teachers' use of technology and the perceived influence principals have upon the integration of instructional technology in the classroom. (Doctoral Dissertation, University of Central Florida, 2003). ProQuest Database ID 765033171.

Page-Jones, A. B. (2008). Leadership behavior and technology activities: The relationship between principals and technology use in schools. (Doctoral dissertation, University of Central Florida Orlando, Florida).

Porter, B. (2003). Technology planning: Strategies for stoking the catalysts of change. Learning and Leading with Technology, 30(6), 6-13.

Shannon, L. B. (2011). The relationship between principals' technology leadership and the teachers' use of technology. (Doctoral dissertation Proposal), Southeastern Louisiana University, Hammond, Louisiana.

State Education Department. (2014, February 5). Statistik sekolah. Retrieved from http://www.moe.gov.my

Weber, M. (2006). A study of computer technology and technology leadership of Texas elementary public school principals. (Unpublished doctoral dissertation). University of North Texas, Denton.

\section{Copyrights}

Copyright for this article is retained by the author(s), with first publication rights granted to the journal.

This is an open-access article distributed under the terms and conditions of the Creative Commons Attribution license (http://creativecommons.org/licenses/by/3.0/). 